\title{
Consideraciones sobre la formación y el funcionamiento de las unidades fraseológicas
}

\section{Considerações sobre a formação e o funcionamento das unidades fraseológicas}

\author{
Yessy Villavicencio Simóni (UFT) \\ Ivan Gabriel Grajales Melian ${ }^{\mathrm{ii}}$ \\ Universidad de Oriente, Cuba
}

\begin{abstract}
Resumen: El objetivo del ensayo es reflexionar sobre la formación y el funcionamiento de las unidades fraseológicas en relación con la distinción de variaciones lingüísticas en el aprendizaje y enseñanza de lenguas. Para ello, adoptamos varios estudios (MARTíN, 2000; CASAS; HUMMEL, 2017; PINHEIRO, 2020; PINHEIRO e OLIVEIRA, 2021) que profundizan en las contribuciones teóricas del lingüista Eugenio Coseriu (1981a, 1981b) y la necesidad de abordar las variedades de la lengua en la planificación didáctica de la enseñanza de las unidades fraseológicas del español como lengua extranjera para el desarrollo de la competencia sociolingüística en el estudiante (AYORA, 2017; AGUILERA; SIMÓN, 2017, 2021). Se evidencia la trascendencia de las aportaciones de Coseriu para las investigaciones en el marco de la fraseodidáctica de lenguas extranjeras.
\end{abstract}

Palabras clave: Competencia sociolingüística; español como lengua extranjera; Eugenio Coseriu; unidades fraseológicas; variedades de la lengua.

Resumo: $O$ objetivo do ensaio é refletir sobre a formação e o funcionamento das unidades fraseológicas em relação à distinção das variações linguísticas na aprendizagem e no ensino das línguas. Para isso, adotamos vários estudos (MARTíN, 2000; CASAS; HUMMEL, 2017; PINHEIRO, 2020; PINHEIRO e OLIVEIRA 2021) que aprofundam as contribuições teóricas do linguista Eugenio Coseriu (1981a, 1981b) e a necessidade de abordar às variedades da língua no planejamento didático do ensino de unidades fraseológicas do espanhol como língua estrangeira para o desenvolvimento da competência sociolinguística do aprendiz (AYORA, 2017; AGUILERA; SIMÓN, 2017, 2021). É notória a transcendência das contribuições de Coseriu para as pesquisas no âmbito da fraseodidática das línguas estrangeiras.

DOI: http://doi.org/10.51359/1982-6850.2021.252120 Eutomia, Recife, 30(1): 62-78, Dez. 2021 
Palavras-chave: Competência sociolinguística; espanhol como língua estrangeira; Eugenio Coseriu; unidades fraseológicas; variedades da língua.

\section{Observaciones iniciales}

El ensayo pretende reflexionar acerca de la formación y el funcionamiento de las unidades fraseológicas en relación con la distinción de variaciones lingüísticas en el aprendizaje y enseñanza de lenguas. Seguimos una metodología de revisión de la literatura científica especializada a partir de las publicaciones (MARTíN, 2000; CASAS; HUMMEL, 2017; PINHEIRO, 2020; PINHEIRO e OLIVEIRA 2021) que acentúan el alcance de los postulados teóricos de Eugenio Coseriu (1981a, 1981b) sobre la descripción estructural y funcional de la lengua, así como la necesidad de abordar las variedades de la lengua en la planificación didáctica de la enseñanza de las unidades fraseológicas del español como lengua extranjera para el desarrollo de la competencia sociolingüística en el estudiante (AYORA, 2017; AGUILERA; SIMÓN, 2017, 2021).

Conforme Ayora (2017), Aguilera y Simón (2017, 2021), dicha competencia se interrelaciona con la competencia sociocultural, pues la enseñanza de las lenguas extranjeras no puede verse alejada del contexto sociocultural en el que se establece un vínculo entre el proceso de aprendizaje de la lengua y cultura meta, cuyo propósito es favorecer las habilidades socioculturales y pragmáticas que permitan al alumno la interacción comunicativa de forma apropiada. Se refiere al conocimiento de las variedades de registro de acuerdo con los factores contextuales y las normas sociales y culturales de interacción, y la competencia funcional al conocimiento de las convenciones que rigen la realización adecuada de las funciones de la lengua, e integran la competencia comunicativa. Teniendo en cuenta los planteamientos de Moreno (1994, p. 118), "la adquisición de la competencia comunicativa se realiza principalmente a través de la interacción comunicativa, que a su vez contribuye a la construcción progresiva de la identidad social de los hablantes y del significado social de los usos lingüísticos." Es por ello que es necesario trabajar la contextualización socio-situacional y las variedades sociales y dialectales de la lengua en su enseñanza, pues permite la adquisición del funcionamiento en su contexto social para poder enfrentarse luego con todas las situaciones imprevistas. 
En este orden, consideramos pertinentes las perspectivas teóricas del reconocido lingüista Eugenio Coseriu en el complejo campo de la enseñanza de lenguas extranjeras y las implicaciones para el estudio sistemático sobre la perspectiva funcional de la variación lingüística dentro del ámbito de la Sociolingüística como disciplina de interés creciente en la actualidad. Pinheiro (2020, p. 8) enfatiza que los postulados de Coseriu revelan "la necesidad de una lingüística integral, es decir, una lingüística que debe dar cuenta de los diferentes aspectos que intervienen en el complejo funcionamiento de la lengua, ordenando estos aspectos en una marca homogénea y unitaria".

Coseriu (1981a) afirma que pueden diferenciarse tres tipos de saberes lingüísticos autónomos, con normas propias y diferentes: saber elocucional o saber hablar en general, independientemente de tal o cual lengua; saber idiomático o saber hablar una lengua; y saber expresivo o saber hablar en determinadas circunstancias. En el estudio de un idioma extranjero, el saber elocucional forma parte de los conocimientos previos del alumno. El saber idiomático se alcanza cuando es posible expresarse correctamente en la lengua de que se trate. Y, por último, el saber expresivo depende de la habilidad o capacidad de que el uso lingüístico se adecue a las situaciones (uso apropiado) y la posibilidad de captar y expresar no solo el significado que viene dado por la expresión lingüística sino también el que depende de determinaciones extralingüísticas (intención del hablante, conocimiento de la realidad circundante, expresiones hechas, entre otras).

Por ende, la lengua puede presentar en el habla distintas variedades, resultado de diversos factores geográficos, socioculturales y contextuales que se producen en el proceso comunicativo (Coseriu, 1981b). Los factores determinantes de estas variaciones lingüísticas son las diferencias de extensión geográfica o diferencias diatópicas (criterio territorial), diferencias entre las capas socio-culturales de la comunidad lingüística o diferencias diastráticas (criterio estratificacional o propiamente sociológico), y diferencias entre los tipos de la modalidad de expresión o diferencias diafásicas (criterio estilístico o de la modalidad de expresión) (FIGUEROA, 1983).

Existe una gran diversidad de dialectos y hablas locales, pues la variación de las lenguas aparece condicionada por el lugar geográfico en el que se hablan. Esto significa que una lengua presenta diferencias dialectales, localizadas geográficamente, lo quedetermina las variedades diatópicas de la lengua. Según el carácter social de la lengua, esta posee 
diversos niveles de uso fijados por factores socioculturales. Las variedades diastráticas indican las diferencias de expresión observadas en los hablantes pertenecientes a distintos niveles culturales. En consecuencia, el nivel sociocultural del hablante determina el nivel de lengua empleado o modalidad de uso del lenguaje. Desde la perspectiva de Coseriu (1981b, p. 118-119), "en cada nivel de lengua se registrarán diferencias diatópicas y diafásicas y en cada estilo de lengua habrá diferencias diatópicas y diastráticas".

De ahí que las diversas variedades sociales o diastráticas (niveles) estén determinadas no solo por el grado de instrucción y conocimiento de la lengua sino también por otros factores sociológicos como la edad y el sexo, así como por la situación comunicativa y el ámbito social y cultural en el que vive. Se plantea que el entorno también puede dar lugar a variedades sociales como lengua rural y urbana (Coseriu, 1981a, 1981b).

El conocimiento de las variedades situacionales o diafásicas que involucran cambios en el lenguaje, como el grado de formalidad de las circunstancias, entendido como la estricta observancia de las reglas, normas y costumbres en la comunicación lingüística, debe ser objeto de aprendizaje en lenguas extranjeras entre los aspectos sociolingüísticos a trabajar (AGUILERA; SIMÓN, 2021). En este sentido, las variedades diafásicas incluyen los registros o estilos de habla, cuyo dominio le permite al usuario de la lengua adecuar su uso lingüístico a las distintas situaciones comunicativas. Coseriu (1981b, p. 122) explica que el hablante usa estilos de lengua distintos, "conoce y puede realizar técnicas diatópica y diastráticamente diferentes de la suya propia."

La noción de registro se define por dos tipos de rasgos: situacionales (externos a la lengua y que determinan el tipo de variedad lingüística que se debe emplear) y primarios (definen dicha variedad en cuanto hecho comunicativo) (ALBELDA; COLOMER, 2006). La situación de cada acto comunicativo hace que el hablante seleccione un determinado nivel de lengua con el objetivo de adecuarse a sus interlocutores. Este hecho explica la existencia de un nivel o registro formal y de un nivel o registro informal o coloquial.

De acuerdo con los rasgos situacionales y primarios que caracterizan el registro, el registro formal presenta mayoritariamente los siguientes rasgos: relación social y/o funcional de desigualdad entre los interlocutores, relación vivencial de distancia, marco de interacción no familiar o no cotidiano, temática especializada, finalidad transaccional, planificación discursiva y tono formal. Por su parte, el registro informal se caracteriza por los rasgos 
contrarios: relación social y/o funcional de igualdad entre los interlocutores, relación vivencial de proximidad, marco de interacción familiar o cotidiano, temática no especializada y/o cotidiana, finalidad interpersonal, ausencia de planificación y tono informal (BRIZ, 1996; ALBELDA; COLOMER, 2006; AGUILERA; SIMÓN, 2017, 2021).

Consideraciones sobre las unidades fraseológicas en la enseñanza del español como lengua extranjera: aproximación a las variedades de la lengua para el desarrollo de la competencia sociolingüística

La formación y el funcionamiento de las unidades fraseológicas en tanto componentes esenciales de la estructura lingüística y objeto de estudio de la Fraseología constituye uno de los temas más amplios dentro del análisis de la vinculación estrecha del lenguaje y la sociedad, a partir de las concepciones de disciplinas como la Sociolingüística y la Lingüística Aplicada a la didáctica del español como lengua extranjera. Igualmente, diversas publicaciones en Fraseodidáctica destacan la relevancia de integrar y priorizar la dimensión idiomática en el aprendizaje del español como lengua extranjera (en adelante ELE). Las aportaciones de los análisis sociolingüísticos son eficaces para el conocimiento funcional de las unidades fraseológicas (en adelante UF) en comunidades socioculturales concretas, de ahí la relevancia que adquiere el tratamiento de estas unidades en el aprendizaje de una lengua extranjera para la solución de necesidades comunicativas concretas, básicamente interpersonales, debido a las dificultades que presenta su estudio.

Cabe señalar que el término de UF engloba las locuciones, fórmulas rutinarias, colocaciones y paremias (proverbios, refranes y modismos), que imprimen valores significativos a la variante conversacional del lenguaje. Estas unidades léxicas compuestas equivalen al sintagma, poseen estabilidad semántico-sintáctica, pueden pertenecer a varios tipos categoriales y cumplen diversas funciones sintácticas (CORPAS, 1996; PENADÉS, 1999; SIMÓN; GRAJALES, 2012; AGUILERA, SIMÓN, 2021). Se enmarcan dentro del "discurso repetido" según los postulados teóricos de Coseriu (1981b, p. 113), entendido como "todo lo que tradicionalmente está fijado como "expresión", "giro", "modismo", "frase" o "locución" y cuyos elementos constitutivos no son reemplazables o re-combinables según las reglas actuales de la lengua." De este modo, Coseriu (1981b) distingue tres tipos de unidades del 
discurso repetido: (1) equivalentes de oraciones (refranes, proverbios, frases metafóricas, dichos); (2) equivalentes de sintagmas; y (3) equivalentes de palabras.

Vale detenerse a considerar cómo incide el concepto de saber expresivo o saber hablar de Coseriu (1981a) en la utilización de las unidades fraseológicas en determinadas circunstancias. Zuluaga (2002) revela la pertinencia de este concepto y explica que su uso implica la ejecución del sistema funcional de la lengua y de la norma lingüística social de forma simultánea. En otras palabras, el saber expresivo está estrechamente vinculado con el dominio de los registros de habla.

El carácter predominantemente oral de las UF conlleva necesariamente a la aparición de variantes fraseológicas (VF) señaladas por Zuluaga (1980, 2000). Estas transformaciones responden a la diversidad en que viven los hablantes, pues se deben a circunstancias diatópicas, diastráticas y diafásicas, relacionadas con el continuo desarrollo de la lengua. Generalmente, están prefijadas, lo que significa que la variación está determinada y limitada, no se puede alterar y es conocida por los usuarios de la lengua.

Según Zuluaga (1980), estas unidades pueden intercambiar alguno de sus constituyentes mediante variaciones morfológicas, morfosintácticas, sintácticas y léxicas dentro de la misma estructura sintáctica, sin presentar diferencias de significado. Por su parte, Koike (2001) demuestra que entre los casos de variación morfológica se encuentran la variación por derivación y la variación en el número gramatical de los constituyentes, tal como en las colocaciones, que pueden presentar variantes en las que cambia el valor categorial de los elementos constituyentes, pero no su valor léxico, por ejemplo, ajuste de cuentas-ajustar cuentas, prohibir terminantemente-prohibición terminante-terminantemente prohibido, gravemente herido-herido de gravedad-herida grave. Presentan una variación morfosintáctica las locuciones verbales que tienen formas nominales: tomar el pelo > tomadura de pelo, meter la pata > metedura de pata. Por variación sintáctica se entiende aquella variación concerniente al uso de preposiciones (levantarse de/con el pie izquierdo) y artículos (no dar el/su brazo a torcer), al número y orden de los constituyentes (ser uña y carne/carne y uña), y al cambio en la estructura sintáctica (hablar [hasta] por los codos, no caber [ni] un alfiler; hacer la vista gorda > hacerse de la vista gorda). La variación léxica consiste principalmente en la sustitución de una de las unidades léxicas que forman parte de una UF. Las variantes léxicas no necesariamente son diatópicas, aunque las hay que presentan tal 
característica, como: ser uña y mugre (México, Honduras, Panamá, Colombia, Venezuela, Bolivia, Chile) y ser uña y diente (República Dominicana) ilustran variantes diatópicas de la forma ser uña y carne perteneciente al español propio de España y de Cuba; agarrar con las manos en la masa (América) (<coger con las manos en la masa).

Con respecto a las variantes fraseológicas, Carneado $(1985$, p. 53$)$ puntualiza que, en los casos de los refranes y proverbios, a veces "se desmembra" uno de los componentes del fraseologismo, y éste pasa a ser acuñado por el uso en forma incompleta. Así ocurre con el refrán del lobo un pelo, aunque sea del rabo: generalmente sólo se utiliza la primera parte, es decir, del lobo un pelo, mientras que la mayoría del pueblo cubano ignora la segunda parte. Conjuntamente con la eliminación de componentes, en los fraseologismos se interpolan y adicionan elementos que, con frecuencia, confieren mayor expresividad a un determinado fraseologismo. Ejemplo de ello es la UF ser un ñame = ser un ñame con corbata.

Es oportuno destacar que las VF no pueden confundirse con las UF sinónimas (ZULUAGA, 1980, apud MENA, 2003; PERAMOS; BATISTA, 2008), puesto que las variantes fraseológicas poseen igual significado y comparten elementos léxicos, mientras que las unidades fraseológicas sinónimas tienen componentes diferentes y comparten solo el mismo significado. Aunque estas últimas son eventualmente intercambiables en una serie de construcciones sintácticas, a causa de la equivalencia de sus significados, son UF distintas como pasar a mejor vida = estirar la pata (morir). Estas expresiones tienen un mismo significado categorial gramatical, constituyen formas paralelas desde el punto de vista del contenido, pero muy diferentes desde un punto de vista formal.

Como bien señala Carneado (1985), los sinónimos fraseológicos no coinciden en la forma, pero sí en la función; tienen un significado común y se emplean en situaciones análogas. Existen casos en los cuales, en una oración determinada, un giro fraseológico no puede ser sustituido por un sinónimo. Este fenómeno puede estar condicionado por el matiz estilístico del fraseologismo. Al respecto, se considera válida la opinión de Garrido (2006) cuando establece diferencias a partir de los elementos que intervienen en las unidades fraseológicas, atendiendo tanto a la sinonimia como a la antonimia. De esta forma, distingue: a) la sinonimia y antonimia interna o intrafraseológica (entre los signos que componen la expresión fija): sano y salvo; ni vivo ni muerto; y b) externa o interfraseológica (entre dos o más expresiones fijas): no mover un dedo = cruzarse de brazos; tener la sartén por el mango = 
llevar la voz cantante = llevar la batuta = llevar los pantalones. En el caso de esta serie sinonímica se trata de expresiones fijas de estructura formal diferente y significado idéntico o semejante. Sin embargo, los fraseologismos antónimos recibir a alguien con los brazos abiertos y dar a alguien la espalda son diferentes en su estructura y significado.

Garrido (2006) confirma que se debería diferenciar la sinonimia y antonimia de significado o de lengua, de la sinonimia y antonimia de sentido o de habla. Mientras que la primera se explica atendiendo a las relaciones que se establecen entre los significados de las palabras, independientemente de cualquier realización contextual, la segunda se manifiesta a partir de las relaciones que representan algún tipo de semejanza o equivalencia (sinonimia) u oposición (antonimia) entre diferentes términos, teniendo en cuenta cualquier factor de tipo pragmático, fundamentalmente el contexto y el conocimiento del mundo compartido por los hablantes. El contexto situacional permite revelar el uso fraseológico de la combinación por medio de datos extralingüísticos cuando ni el oracional ni el supraoracional pueden hacerlo. Resulta indispensable que el receptor esté familiarizado, en cierta medida, con la situación que se describe en el contexto dado (TRISTÁ, 1988). Es por esto que resulta apropiado hablar de significados sinonímicos y antonímicos frente a sentidos sinonímicos y antonímicos.

La modificación o manipulación creativa de las unidades fraseológicas de forma consciente y voluntaria por los hablantes con el fin de resolver necesidades comunicativas produce las UF desautomatizadas. Mena (2003) señala que las variantes suelen confundirse con las UF desautomatizadas. Estas surgen a partir del fenómeno de variabilidad fraseológica llamado desautomatización, factor del carácter dinámico, adaptativo e inestable de las unidades fraseológicas. El concepto de desautomatización constituye una muestra de la creatividad del lenguaje fraseológico y se refiere al fenómeno por el que una UF se ve total o parcialmente alterada, motivando la percepción de los receptores o lectores hacia el mensaje.

Zuluaga (2002) plantea que depende de ciertas variaciones en su estructura interna, como la sustitución de un componente o de las alteraciones de su combinabilidad con otros elementos del discurso. La creación de una expresión fraseológica exige una formulación adecuada, lo que implica ajustarse a los esquemas formales productivos y favorecedores de la creación, memorización, interpretación y simplificación de los fraseologismos; y a los modelos cognitivos idealizados que organizan el conocimiento del mundo (RUIZ, 2000). 
En este sentido, cabe agregar que el proceso de desautomatización tiene su origen en la intención del emisor, quien realiza modificaciones creativas en la UF impulsado por una determinada finalidad y atendiendo a las posibilidades de relación significante - significado - sentido, y termina cuando la UF desautomatizada manifiesta un conjunto de efectos de naturaleza semántica, metalingüística, estilística y pragmática, muy relacionados con la expresividad, causa de la formación de las UF. En general, transmiten sentimientos, actitudes o juicios del hablante, es decir, verbalizan contenidos afectivos, e imprimen mayor espontaneidad, vivacidad y fluidez al discurso, que resulta ser más auténtico.

Muchas unidades fraseológicas expresan una valoración del hablante con más frecuencia negativa que positiva, o suponen un mayor grado de precisión e intensidad en la forma de hablar utilizada normalmente, todo ello hace su aplicabilidad más restringida. El hablante no siempre comunica explícitamente lo que piensa, ya que espera que el oyente infiera adecuadamente los significados implícitos de las UF, guiándose por lo que se dice, más todos sus conocimientos acerca del contexto, de lo que suele ocurrir y puede esperarse en una situación equivalente, aparte de que existen convenciones de uso, de acuerdo a las cuales no siempre lo dicho y lo significado intencionalmente coinciden (GARCÍA, 2001).

Precisamente, la mayor dificultad que encuentra el aprendiz para comprender el significado de las unidades fraseológicas radica en la función expresiva que proporciona un matiz emocional valorativo o estilístico, y está motivada por las implicaciones de tipo cultural que encierra. Cuando se aprende una lengua extranjera, los efectos propios de las unidades desautomatizadas pueden resultar poco comprensibles para el usuario de la lengua debido al alto valor metafórico que muchas de las expresiones contienen, lo cual significa que el estudiante debe realizar un proceso de comprensión para identificar el verdadero sentido del conjunto metafórico, que depende del contexto comunicativo y no de su constitución léxica y morfosintáctica.

Cárdenas y Tristá (1986) afirman que la metaforización desempeña un importante papel en la fraseología y constituye la fuente más propicia para el enriquecimiento del caudal fraseológico de una lengua. Por medio del proceso de metaforización, una característica, propiedad o estado inherente a un objeto pasa a caracterizar a otro que bien puede pertenecer a una clase totalmente diferente, sobre la base de la semejanza o la analogía, de rasgos existentes en el reflejo conceptual del objeto designado y en el significado de la 
palabra reinterpretada. Para analizar el modo de revelación de la metáfora en la formación de las UF, es necesario conocer la interrelación existente entre los significados de estas unidades y los valores semánticos de sus componentes.

Al metaforizarse las palabras que constituyen una combinación de palabras, cada palabra pierde su función nominativa característica y la combinación en su conjunto adquiere una nueva función nominativa, de modo que ocurre la desemantización. Como resultado de la reinterpretación de la imagen de la combinación libre de palabras, surge un nuevo signo complejo con sus características semánticas y estructurales propias.

Una particularidad característica de las UF es la motivación metafórica, vinculada a la comprensión de la imagen surgida del significado recto de la combinación de palabras. No obstante, un fraseologismo puede perder con el tiempo su motivación metafórica porque se olvide el nexo metafórico o la imagen que las motivó, o sea, se pierda el referente y el significado original que ha dado pie a la metáfora (CARNEADO, 1985).

Hay que advertir que algunos fraseologismos se caracterizan principalmente por su función icónica o iconicidad, como bien indica Zuluaga (2002). Esta consiste en presentar un contenido mediante una imagen concreta de orden visual. Es el caso de los fraseologismos comparativos creados sobre la base de similitud a partir de la metáfora y relacionada con el carácter simbólico que prevalece en las designaciones de los animales que contienen. Por ejemplo: hablar como una cotorra con el significado de locuacidad. El enunciado comparativo, aun siendo influido por la metaforización, resulta interpretable ya que no se produce una desemantización total del término de comparación y es relativamente fácil de reconocer en un texto. Posee un sentido literal (la imagen) y un sentido metafórico (idiomático o semiidiomático).

Se comparte el criterio de Cárdenas y Tristá (1986) cuando plantean que el desconocimiento, por parte del interlocutor/lector, del significado de una expresión dada o, en ocasiones, hasta su incapacidad o imposibilidad de representar y buscar por sí mismo la explicación de una imagen, origina una ruptura en la coherencia del discurso y, por ende, una laguna en el proceso de comunicación. Sin lugar a duda, las asociaciones llevadas a cabo con el fin de interpretar el significado de naturaleza traslaticia de una expresión desconocida pueden ser diferentes, puesto que en ellas prima lo subjetivo, la manera individual de cada hablante de reaccionar ante lo que le rodea. Además, el significado figurado de las UF está 
motivado por su conocimiento tácito de las metáforas conceptuales subyacentes, las cuales exigen que los interlocutores compartan distintos referentes culturales y son expresión de determinados conceptos y percepciones de la realidad cognitiva, que se manifiestan mediante la lengua.

Para entender y dominar las implicaciones comunicativas de la connotación metafórica y seleccionar la más adecuada a las necesidades contextuales, se requiere más de la competencia comunicativa, los conocimientos previos y las experiencias acumuladas del mundo, que de la competencia lingüística. De este modo, el discente es capaz de interpretar y usar apropiadamente el significado de determinada UF en relación con las funciones y variedades de la lengua y con las suposiciones culturales en la situación comunicativa.

Un aspecto que puede provocar cierta confusión, incluso entre los hablantes nativos del español de varios países, es la existencia de unidades fraseológicas que adquieren significados diferentes según la zona donde se emplee. Se trata del fenómeno de la homonimia diatópica de las expresiones fijas del español (KOIKE, 2003). Los fraseologismos con homónimos libres pueden ser diversos, pero en todos ellos desempeña un papel principal el contexto. El contexto situacional permite revelar el uso fraseológico de la combinación por medio de datos extralingüísticos cuando ni el oracional ni el supraoracional pueden hacerlo. Resulta indispensable que el receptor esté familiarizado, en cierta medida, con la situación que se describe en el contexto dado (TRISTÁ, 1988).

El fenómeno de la sinonimia es uno de los índices de la polisemia de las UF de acuerdo con los registros y contextos, la cual origina el fenómeno de la ambigüedad o dilogía. Ullmann (1970) explica que la mayoría de las ambigüedades se aclaran por el contexto y, en el lenguaje hablado, por la entonación. La polisemia es un factor inapreciable de economía y flexibilidad en el lenguaje y surge a partir de la metáfora y la metonimia o contigüidad de sentidos. La polisemia de una expresión puede desarrollarse sobre la base del significado de otra unidad fraseológica.

El aprovechamiento metalingüístico consciente de este fenómeno induce en el receptor asociaciones léxicas connotativas que amplían expresivamente el grado informativo del mensaje para lograr su correcta comprensión, obligándole a relacionar metalingüísticamente los varios significados implicados. Los sentidos de una unidad fraseológica se actualizan por el receptor en un contexto determinado de acuerdo con las 
necesidades comunicativas.

Algunas UF poseen un sinónimo en un determinado contexto, pero no en otro, por lo que el alumno de ELE corre el riesgo de generalizar el uso de la UF a contextos inapropiados (CARNEADO, 1985). Justamente, la polisemia de las UF se traduce en dificultades para el sujeto que aprende, quien debe discriminar los distintos significados de una misma unidad y saber utilizarla en diferentes contextos. De este modo, utilizará la unidad polisémica únicamente con un significado y evitará su uso en otros contextos en los que, según su percepción, el sentido resultará ambiguo o incompatible con la situación.

En el español americano existen formas lingüísticas ausentes en el español peninsular que constituyen un tipo de americanismos (JÁIMEZ, 2003). De ello se infiere la necesidad de que el profesor explique el ámbito de uso y el contraste geográfico de las unidades, teniendo presente que existe una clara división geográfica entre España y América para expresar un mismo concepto. Por un lado, las expresiones de ámbito general son aquellas que se emplean con el mismo significado idiomático casi en toda el área de habla hispana. Por otro, las expresiones locales son las que se usan en determinadas zonas. Frente a las expresiones fraseológicas que suelen usarse en España, las hay que se emplean en América. De igual manera, existen expresiones cuyo ámbito de uso queda restringido a un único país o región. Hay expresiones autóctonas de algunas zonas de habla hispana que no se emplean en otras (KOIKE, 2001).

En las clases de español como lengua extranjera se hace cada vez más evidente la necesidad de abordar la realidad plural de la lengua española a partir de la explicación de los ejes diatópico, diastrático y diafásico de la lengua por parte del docente, de forma tal que posibilite ampliar la competencia sociolingüística en los estudiantes. Sin embargo, las variedades internas de la lengua no siempre reciben el tratamiento más adecuado en el aula. Desde el punto de vista metodológico, no existe una propuesta uniforme y verdaderamente elaborada sobre esta cuestión para su planteamiento en la enseñanza de $E L E_{i}$ un gran número de profesores de español carecen de una formación lingüística, es decir, no cuentan con formación teórica ni con información práctica acerca del tratamiento que puede y debe hacerse de las variedades del español (LLAMAS; MARTíNEZ, 2000).

Por una parte, algunos trabajos proponen la inclusión en el aula de ELE de transliteraciones o transcripciones de conversaciones orales reales como muestras del 
registro coloquial o informal, aunque en determinados casos la conversación como modalidad discursiva también se puede realizar en un ámbito más formal (GARCÍA, 2001; ALBELDA; COLOMER, 2006; SIMÓN; GRAJALES, 2012; AGUILERA; SIMÓN, 2021). Un aprovechamiento efectivo de este recurso didáctico posibilita enfrentar al alumno a contextos reales, donde puede analizar los distintos niveles de complejidad de las expresiones lingüísticas en relación con las intenciones expresivas y comunicativas, e igualmente enseñar los rasgos fonéticos de una región determinada (variante diatópica), específicamente a estudiantes que aprenden la lengua en contextos de inmersión.

Asimismo, el aprendizaje de la lengua mediante textos conversacionales activa el enfoque comunicativo, el cual insiste en contextualizar los hechos comunicativos y tener en cuenta los rasgos que definen cada situación de habla. No obstante, este enfoque a veces limita el uso de la lengua exclusivamente a situaciones de carácter informal en las que existe un predominio de ciertos recursos lingüísticos propios de lo coloquial, con el consiguiente olvido del registro formal, lo que de cierta forma resulta motivo de dificultades para que el estudiante de ELE aprenda a comunicarse de forma efectiva y apropiada en situaciones reales con hablantes nativos (LLAMAS; MARTíNEZ, 2000).

Por tanto, el docente de ELE debe presentar las UF frecuentes en la comunicación oral mediante técnicas y contextos que permitan relacionar unas con otras en aras de mejorar y agilizar su aprendizaje y uso. Las actividades que se elaboren con este fin favorecerán en gran medida las estrategias de asociación de las unidades objeto de análisis a través de sus redes con múltiples asociaciones semánticas y pragmáticas. Se trata de privilegiar la noción de contexto desde un trabajo explícito del léxico basado en un procesamiento mental por parte del estudiante en el cual se presta atención no solo a la forma y el significado de las palabras, sino también al uso y las restricciones de cada unidad léxica, en combinación con su aprendizaje implícito.

\section{Consideraciones finales}

Hemos apuntado la trascendencia de las aportaciones de Coseriu (1981a, 1981b) para las investigaciones en el marco de la fraseodidáctica de lenguas extranjeras, especialmente, el alcance teórico y la dimensión práctica sobre la conceptualización de la variación lingüística 
así como la distinción del discurso repetido que engloba las unidades fraseológicas. Las aportaciones del lingüista son ciertamente válidas para la comprensión estructural y funcional de las UF a partir de la semántica estructural y sus implicaciones en la sociolingüística aplicada a la enseñanza de lenguas extranjeras.

Aunque estas unidades léxicas se usan en todos los registros dada su diversificación diatópica, diastrática y diafásica, algunas de ellas son características del registro coloquial. Los registros lingüísticos, al igual que las connotaciones o los aspectos metafóricos, son fruto de las relaciones sociales, de las actitudes y de los valores culturales de cada comunidad de hablantes. Están determinados por la situación de uso y el contenido comunicativo. En una conversación, de acuerdo con los temas que vayan apareciendo, pueden alternar diferentes registros o niveles de empleo. Cuanto más se dominen las modalidades lingüísticas y los registros, más alto será el nivel de lengua de los alumnos. De esta manera, se favorece el desarrollo del saber expresivo (Coseriu, 1981a) y se practica el componente sociolingüístico y pragmático, más difícil de transmitir cuando el contexto de enseñanza no es el de la lengua meta.

Por tales razones, adquiere relevancia el estudio de las variedades de la lengua en la enseñanza de las unidades fraseológicas en tanto posibilitan la comprensión de su uso lingüístico, en virtud del desarrollo de la competencia sociolingüística. Para lograr la comunicación eficiente del estudiante de ELE, se hace necesario la explicación adecuada y detallada de las variedades de la lengua por parte del docente, quien debe conocer y profundizar en los términos relacionados con dichas variedades, de manera que pueda transmitir a sus estudiantes la funcionalidad y diversidad idiomática. Así pues, el profesor debe indagar constantemente en las propuestas didácticas que aportan posibilidades de análisis de la variación lingüística en el proceso de enseñanza-aprendizaje de la lengua.

\section{Referencias}

AGUILERA, Y. Gámez; SIMÓN, Y. Villavicencio. Tratamiento didáctico del registro coloquial para el desarrollo de la competencia sociolingüística en el nivel elemental de ELE. En: Nuevos estudios sobre comunicación social, v. 2. Santiago de Cuba: Centro de Lingüística Aplicada, 2017. p. 533-536.

AGUILERA Y. Gámez; SIMÓN, Y. Villavicencio Las fórmulas rutinarias en la enseñanza del 
español como lengua extranjera para principiantes: alternativa didáctica en contexto de inmersión. Decires. Estudios del español como lengua extranjera y culturas mexicana e hispanoamericana, v. 1 , n. 1 , p. 73-96, 2021. Disponible en: <http://132.248.130.174/open/index.php/decires/article/view/307>. Acceso en: 22 sept. 2021.

ALBELDA, M. Marco; COLOMER, M. J. Fernández. La enseñanza de los registros lingüísticos en E/LE. Una aplicación a la conversación coloquial. marcoELE, Revista de Didáctica n. 3, 2006. Disponible en: https://marcoele.com/numeros/numero-3l. Acceso en: 22 sept. 2021.

AYORA, C. Esteban. La competencia sociolingüística y los componentes culturales dentro del proceso del proceso de enseñanza-aprendizaje del español en un contexto de submersión lingüística. Pragmalingüística, n. 25, p. 31-49, 2017. Disponible en: https://revistas.uca.es/index.php/pragma/article/view/3667. Acceso en: 21 jul. 2021.

BRIZ, A. El español coloquial: Situación y uso. Madrid: Arco Libros, 1996.

CARNEADO, Z. V. Moré. La Fraseología en los diccionarios cubanos. La Habana: Editorial de Ciencias Sociales, 1985.

CARNEAdO, Z. V. Moré; TRISTÁ, A. M. Pérez. Estudios de Fraseología. Academia de Ciencias de Cuba: Instituto de Literatura y Lingüística, 1986.

CASAS, M. Gómez; HUMMEL, M. Limitaciones y nuevos retos de la semántica léxica. Rilce: Revista de Filología Hispánica, v. 33, n. 3, 2017.

CORPAS, G. Pastor. Manual de Fraseología española. Madrid: Editorial Gredos, 1996.

COSERIU, E. Lecciones de lingüística general. Madrid: Editorial Gredos, 1981a.

COSERIU, E. Principios de Semántica estructural. Madrid: Editorial Gredos, 1981b.

FIGUEROA, M. Esteva. La dimensión lingüística del hombre. Problemas de historia y actualidad. La Habana: Editorial de Ciencias Sociales, 1983.

GARCÍA, M. T. Godoy. La variación lingüística y la enseñanza del español: algunas propuestas didácticas. En: ESTEBÁNEZ CALDERÓN, E. (ed.). El hispanismo en la República Checa II, 2001, p. 13-26. Disponible en: http://hispanismo.cervantes.es/documentos/Librosemana/AJIHLE2006.pdf. Acceso en: 21 jul. 2021.

GARRIDO, M. del C. Rodríguez. Sinonimia y antonimia: significado y sentido. En: Actas del XXXV Simposio Internacional de la Sociedad Española de Lingüística, 2006. Disponible en: http://wwwz.unileon.es/dp/dfh/SEL/actas.htm. Acceso en: 21 jul. 2021.

JÁIMEZ, R. ¿Refranes postmodernos? Anuario de Lingüística Hispánica, v. XIX-XX, 20032004, p. 123-124. 
KOIKE, K. Variación fraseológica del español. En: Actas-I, VII Simposio Internacional de Comunicación Social, Santiago de Cuba, 2001, p. 19-22.

KOIKE, K. Las unidades fraseológicas del español: su distribución geográfica y variantes diatópicas. Revista EPOS, XIX, 2003, p. 4-65.

LLAMAS, C. Saíz; MARTÍNEZ, C. Pasamar. La diversidad estilística: una propuesta para su tratamiento en el aula de ELE. ASELE, Actas XI, p. 481-491, 2000. Disponible en: https://cvc.cervantes.es/ensenanza/biblioteca ele/asele/pdf/11/11 0481.pdf. Acceso en: 21 jul. 2021.

MARTÍN ZORRAQUINO, M. A. Norma y variación lingüísticas en la enseñanza de E/LE. ASELE. Actas $\mathrm{XI}$ 2000. Disponible en: https://cvc.cervantes.es/ensenanza/biblioteca ele/asele/pdf/11/11 0007.pdf. Acceso en: 21 jul. 2021.

MENA, F. Martínez En torno al concepto de desautomatización fraseológica: aspectos básicos. Tonos. Revista Electrónica de Estudios Filológicos, no. 5, 2003. Disponible en: http://www.um.es/tonosdigital. Acceso en: 21 jul. 2021.

MORENO, F. Fernández. Aportes de la Sociolingüística a la enseñanza de lenguas. Revista de Estudios de Adquisición de la Lengua Española (REALE), Universidad de Alcalá de Henares, Departamento de Filología, no. 1, 1994, p. 107-135.

PENADÉS, I. Martínez. La enseñanza de las unidades fraseológicas. Madrid: Arco Libros, 1999.

PERAMOS, N. Soler; BATISTA, J. J. Rodríguez.Unidades fraseológicas y variación. Ogigia. Revista electrónica de estudios hispánicos, n. 3, 2008. Disponible en: http://www.ogigia.es/OGIGIA3_files/OGIGIA3_PERAMOS_Y_BATISTA.pdf. Acceso en: 21 jul. 2021.

PINHEIRO, C. Lopes; OLIVEIRA, J. Santos de. A coerência segundo a perspectiva da teoria da linguagem de Eugenio Coseriu. Revista do GELNE, v. 23, n. 1, 2021.

PINHEIRO, C. Lopes. Ferdinand de Saussure et Eugenio Coseriu: propositions pour une linguistique intégraliste. SHS Web of Conferences 78, Congrès Mondial de Linguistique Française CMLF, 2020.

RUIZ, L. Gurillo. Un enfoque didáctico de la fraseología española para extranjeros. Aprendizaje y enseñanza de una segunda lengua. En: COPERÍAS, M. J; REDONDO, J.; SANMARTÍN, J. (Eds.). Aprendizaje y enseñanza de una segunda lengua. Quaderns de Filologia. València: Universitat de València, 2000, p. 259-275.

SIMÓN, Y. Villavicencio; GRAJALES, I. G. Melian. Premisas en torno a la programación de actividades para el estudio de los fraseologismos en las clases de español como lengua 
extranjera en la Universidad de Oriente. Santiago, 124, p. 37-49, 2012. Disponible en: https://santiago.uo.edu.cu/index.php/stgo/article/view/1474/1448. Acceso en: 21 jul. 2021.

TRISTÁ, A. M. Pérez. Fraseología y contexto. La Habana: Editorial de Ciencias Sociales, 1988.

ULLMANN, S. Semántica (Introducción a la ciencia del significado). Madrid: Ediciones Aguilar, 1970.

ZULUAGA, A. Introducción al estudio de las expresiones fijas. Frankfurt: Max Hueber Verlag, Tubinga, 1980.

ZULUAGA, A. Los "enlaces frecuentes" de María Moliner. Observaciones sobre las llamadas colocaciones. Lingüística española actual, XXIV, pp. 97-114, 2002.

\footnotetext{
' Doctoranda en Letras: Ensino de Língua e Literatura/UFT (PPGL) por la Universidade Federal de TocantinsUFT, Campus de Araguaína, Tocantins, Brasil. Máster en Enseñanza del Español como Lengua Extranjera (ELE) y Licenciada en Letras por la Universidad de Oriente, Cuba. Bolsista de Coordenação de Aperfeiçoamento de Pessoal de Nível Superior (Capes), Brasil.

ORCID: https://orcid.org/0000-0001-9006-7775.

E-mail: villavicencioys6g@gmail.com.

ii Doctor en Ciencias Literarias por la Universidad de Oriente-UO, Cuba.

ORCID: https://orcid.org/0000-0002-4163-112X.

E-mail: melian.ivan77@gmail.com.
}

Recebido em 21/10/21

Aprovado em 24/12/21

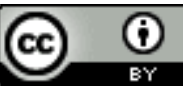

Todo conteúdo da Revista Eutomia está sob a Licença Creative Commons Atribuição 4.0 Internacional. 